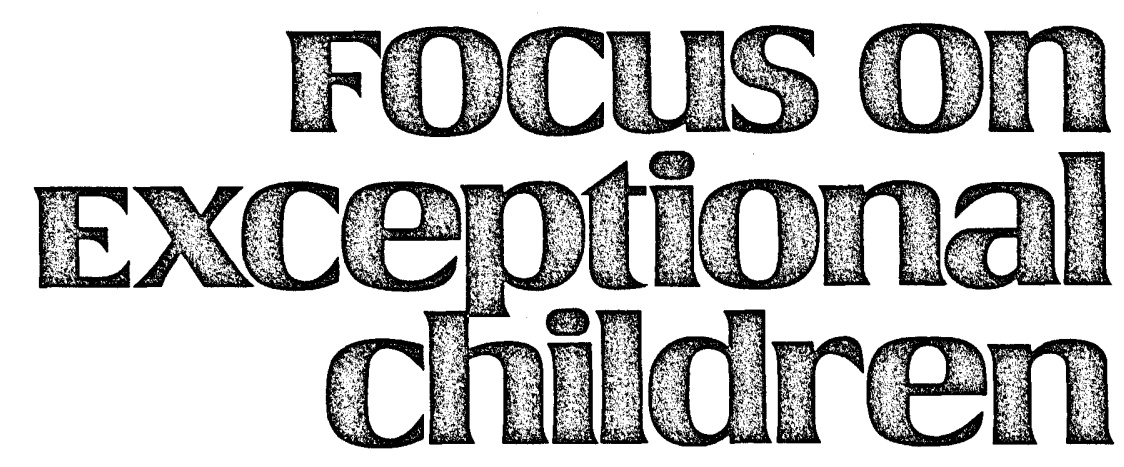

\title{
Special Education for Language Minority Students
}

\author{
Giselle B. Esquivel and Roland K. Yoshida
}

Since the appearance of Dunn's (1968) article questioning the practice of placing mildly retarded children in self-contained special classes, the field of special education has been engaged in critical self-evaluation. Dunn argued against special classes for educable mentally retarded (EMR) children on the basis of the following:

1. The composition of those classes typically consisted of a disproportionate number of minority children who were not "truly" retarded.

2. The special classes had not resulted in the academic and personal growth expected.

3. The practices of identifying and labeling resulted in negative self-fulfilling prophecies for those so labeled.

Dunn's article focused attention on the criteria used for classifying children as handicapped and on the services provided as a result of such classification. The merits of his arguments have been discussed elsewhere (MacMillan, 1971, 1982). It is not surprising that soon thereafter parents of Spanish-speaking students in California were able to obtain a consent decree requiring bilingual children to be tested in their native language. ${ }^{1}$ Besides the language issue, the content of the intelligence tests themselves was challenged as being culturally biased. ${ }^{2}$ The consent decree issued as part of the original Larry $P$. case required reevaluation and, if appropriate, decertification of EMR students who did not meet new state guidelines. In practice, decertification was effected if a student's IQ was higher than 70 (Meyers, MacMillan, \& Yoshida, 1978). Although the numbers of EMR students declined over $50 \%$, the proportions of minority studentsblacks and Hispanics-did not. Similar enrollment trends have been noted for minority students in learning disabled (LD) classes (Ortiz \& Yates, 1981; Tucker, 1980).

Dr. Esquivel is an Assistant Professor of the Bilingual School Psychology Program, Graduate School of Education, Fordham University, where Dr. Yoshida is Professor and Chairman, Division of Psychological and Educational Services, Graduate School of Education.

1. Diana v. California, C-70-37 RFP, District Court for Northern California (February 1970).

2. Larry P. v. Riles, U. S. L. W. 2033 (June 21, 1972). 


\section{THE SOCIAL SYSTEM PERSPECTIVE}

Why are minority students still over-represented in special education placements? Mercer's (1973) social system view of the learning environment provides some insights. Her explanation was originally applied to how students came to be labeled mentally retarded but has generalized to other special education labels. Basically, every teacher has standards or expectations for what is acceptable behavior in the classroom. When children do not meet those standards, they are referred for special evaluation. Mercer (1971) found that frequently children referred and classified EMR actually had learning problems in reading and math, were hyperactive, and had poor working habits and relationships with peers.

Similarly, in analyzing case records of children decertified as part of the Larry $P$. case, Meyers, MacMillan, and Yoshida (1978) found that, in addition to IQ, the strongest predictors for being classified as retarded were previous retention in regular classes and numerous statements of in-

\section{Focus on
Exceptional children}

FOCUS ON EXCEPTIONAL CHILDREN (ISSN0015-5IIX) (USPS 203-360) is published monthly except June, July, and August as a service to teachers, special educators, curriculum specialists, administrators, and those concerned with the special education of exceptional children. This journal is abstracted and indexed in Exceptional Child Education Resources, and is also available in microform from Xerox University Microfilm. Ann Arbor, Michigan. Subscription rates, $\$ 18.00$ per year. Copyright $\odot 1985$. Love Publishing Company. All rights reserved. Reproduction in whole or part without written permission is prohibited. Printed in the United States of America. Second class postage is paid at Denver, Colorado.

POSTMASTER: Send address changes to:

Love Publishing Company

Executive and Editorial Office

1777 South Bellaire Street

Denver, Colorado 80222

Telephone (303) 757-2579

EDITORIAL BOARD

Edward L. Meyen

University of Kansas

Richard J. Whelan

University of Kansas Medical Center

Stanley F. Love

Publisher
Glenn A. Vergason Georgia State University

Carolyn Acheson Senior Editor appropriate classroom behaviors. Finally, sex differences in referral reasons have been found. Girls are referred more often for academic reasons, while boys are referred more often for behavioral problems (Davis, 1978; Gregory, 1977).

Results of the above studies are still interpreted as focusing the problem on the child. The child's failure to read, to have poor work habits, or to have poor peer relationships leads to the referral (Meyers, MacMillan, \& Yoshida, 1978). Thus, research using the social system perspective has been limited to final outcomes such as referral and placement, which are presumed to be caused by the child's inability to meet expectations.

\section{The Terminology and the Population}

Although many minority students, especially those with a native language different from English (hereafter termed language minority) may indeed have a handicapping condition, we believe that they also have had experiences in the family and community that may not have prepared them to perform school-related academic and social tasks. The term language minority refers to children whose families speak languages other than English, as well as those with varying degrees of bilingualism. In 1976 about 28 million people

\section{STATEMENT OF OWNERSHIP, MANAGEMENT AND} CIRCULATION

Date of Filing: September 30, 1985

Title of Publication: FOCUS ON EXCEPTIONAL CHILDREN

Frequency of Issue: Monthly except June, July, August

Location of Known Office of Publication: 1777 S. Bellaire St., Denver, CO 80222

Location of Headquarters of Publisher: 1777 S. Bellaire St., Denver, CO 80222

Name and Address of Publisher, Editor, and Managing Editor: Stanley F. Love, 1777 S. Bellaire St., Denver, CO 80222

Owner: Stanley F. Love

Extent and Nature of Circulation:

$\begin{array}{lcr}\text { Total No. Copies Printed } & \begin{array}{c}\text { Average No. Copies } \\ \text { Each Issue during } \\ \text { Preceding 12 Months }\end{array} & \begin{array}{c}\text { Single Issue } \\ \text { Nearest to } \\ \text { Filing Date }\end{array} \\ \begin{array}{lcc}\text { Paid Circulation } \\ \quad \text { Sales through Dealers, etc. }\end{array} & 3,825 & 4,000 \\ \quad \text { Mail Subscriptions } & 0 & 0 \\ \text { Total Paid Circulation } & 3,315 & 3,345 \\ \text { Free Distribution } & 3,315 & 3,432 \\ \text { Total Distribution } & 3,565 & 3,682 \\ \text { Office Use and Left Over } & 260 & 318 \\ \text { Total } & 3,825 & 4,000\end{array}$

1 certify that the statements made by me above are correct and complete.

(Signed) Stanley F. Love, Publisher 
in the United States were estimated to communicate primarily through a non-English language. This figure is projected to increase to almost 40 million by the year 2000 (Baca \& Cervantes, 1984). Besides language, non-English speakers probably hold cultural values that differ from those traditionally accepted in American schools.

Even with this background, most language minority children assimilate quickly into the school culture. Some may have difficulty, however, because of their language and cultural backgrounds. They may not have had the opportunity to learn school routines before they enter school or even after they are enrolled (Perlman, Zabel, \& Zabel, 1982). Teachers may assume that their students, regardless of background, should come to school knowing how to behave in classrooms or be willing to learn to do so.

\section{New Approaches}

Some children who may have the capabilities to adjust to classroom situations may not have adjusted because they were never systematically taught to do so. Rather than concluding that these children are handicapped, our approach would be to verify that the children have been introduced to teachers' and schools' expectations and encouraged to behave accordingly. In short, teachers must become aware that they have to adapt instruction to children's backgrounds at the same time children begin to adapt to school standards and procedures.

This change in perceiving the primary source of school learning problems should be a fundamental principle guiding the development of the emerging field of bilingual special education. The onus is upon professionals - not students-to demonstrate that learning can or cannot occur, by employing various techniques and approaches. This principle can affect the functions of bilingual special education teachers in several ways. For example, most of the professional literature focuses on the role of bilingual special education teachers after language minority students have been placed in special education classes. Texts and articles review various ways in which bilingual special education teachers can combine traditional special educational pedagogy with that of bilingual education (Ambert \& Dew, 1982; Baca \& Cervantes, 1984; Omark \& Erickson, 1983; Ortiz, 1984; Rodriguez, 1982). Further, bilingual special education teachers and other bilingual support personnel can also assume a preventive role by helping regular education teachers become aware of the possibility that their usual teaching techniques may be inappropriate for language minority students.
Once teachers are sensitive to their teaching techniques, bilingual special education teachers can demonstrate alternative ways of working with students. We have selected the following promising areas: (a) instruction for language academic achievement, and (b) instruction for developing appropriate social skills. These areas have been discussed in the professional literature, and research has begun to determine whether they are related to student achievement and social adjustment. It is too early to tell under what conditions these approaches are effective. Nevertheless, they will help bilingual special education teachers develop approaches for consulting teachers and design their own instructional techniques based upon the principles of the social system model presented above.

\section{INSTRUCTION FOR LANGUAGE ACADEMIC ACHIEVEMENT}

Learning a second language poses fundamental problems for children. First, children have limited knowledge of certain idioms or vocabulary words and are unaware of differences in grammatical structure between English and the native language. For example, some speech sounds in English that are basically phonetic may not exist in other languages such as Vietnamese (Chin, 1981). These differences may delay acquisition of English speech, although most bilingual children usually acquire English conversational skills within 2 years of residence in the United States.

\section{Increased Learning Time}

Bilingual children may require 5 to 7 years to acquire aspects of language that are related to academic and cognitive tasks required for school learning (Cummins, 1980). Because of the effort needed to learn a new language, bilingual children initially may demonstrate lower levels of achievement relative to their English-speaking peers. Even when they master English, they probably will need extra time to reach the achievement levels of their monolingual peers. This is especially true for students who have had limited exposure to formal learning experiences and verbal interaction or have poorly developed literacy skills in their native language.

\section{Selecting the Appropriate Language}

Besides teacher sensitivity to increased learning time, Ortiz (1984) has raised a basic issue about selecting the 
appropriate language to be used for these children and whether instruction should be monolingual or bilingual. She found that children who show serious language problems in both languages appear to benefit most from instruction in the predominant language of the local community in which they live. For children with a diagnosed language disorder, Langdon (1983) found that instruction in their native or most dominant language was better than bilingual instruction.

\section{A Meaningful Experiential Context}

Cummins (1984) cited various studies supporting an approach that actively involves students in using language within a meaningful experiential context (what he termed the reciprocal interaction model) rather than by traditional didactic/lecture methods. The model's basic instructional strategy is to teach conceptual skills, rather than factual information, through discussions with students. For example, DeAvila and Duncan (1982) developed the Finding Out/Descubuvieto Program, to teach conceptual skills in math and science. Children are organized in small groups at learning centers for 14 weeks. They are encouraged to question and discuss lesson material in both English and Spanish. Findings from this experimental program indicated that all students made progress, but the lowest functioning students made the most significant gains in performance. Moreover, the amount of students' verbal interaction was significantly related to academic gain. These results support the argument of not only emphasizing conceptual skills as the content of instruction, but also of allowing bilingual students, especially those low in achievement, to practice their language skills through discussion.

\section{The Role of Motivation, Lack of Ability, and Reading Approaches/Methods}

Similarly, Gallimore and his associates (Gallimore, Boggs, \& Jordan, 1974; Gallimore \& Tharp, 1981; Gallimore, Tharp, Sloat, \& Klein, 1982; Tharp, 1982; Tharp \& Gallimore, 1976) have conducted a long-term investigation into improving the reading achievement of Hawaiian children who were wholly or partially of Polynesian ancestry. These children typically scored in the lowest $4 \%$ on standardized reading achievement tests. District administrators believed that the low scores were related to a lack of motivation or lack of ability to learn in standard English. These reasons are similar to those often given with regard to students referred for special education.

In terms of the motivation problem, the researchers found that the Hawaiian children behaved in ways that were unacceptable in most classrooms. They were extroverted, appeared not to care about instructional activities, and generally avoided adult contact. After determining what behaviors were desirable, teachers were asked to administer positive reinforcement whenever appropriate behavior occurred. This strategy increased the students' adaptive behavior in classes but did little to increase their achievement.

Thus, the researchers began to focus on the question of language. In one study, students were tape recorded. They were found to be fluent in their native dialect, as well as able to understand standard English. When children 5 to 8 years of age were asked to repeat sentences spoken to them in both the native dialect and standard English, the number correctly repeated in both dialects increased by age group with no differences between them. Language deficiency was ruled out as a cause for low achievement.

With motivation and language deficiencies ruled out, the researchers experimented with various reading approaches and materials. Traditional reading approaches such as developing word attack or phonetic skills and reading from a basal text did very little to interest the children or raise their achievement levels. These types of reading activities had little to do with the life experiences of the Hawaiian children. Students, however, responded to reading assignments when teachers related the topic of the reading passage to the children's community and asked them about their own experiences. Most of the reading time was spent in small groups discussing the reading passage regardless of dialect. Teachers emphasized comprehension of the passage rather than sight reading. Students participating in this method were attaining reading scores in the 40th to 50th centiles as contrasted with control students, who never attained scores higher than the 25 th centile.

\section{The Teacher-Student Relationship}

This project and those of Cummins (1984) and DeAvila and Duncan (1981) demonstrate that the teacher-student relationship is a two-way communication system (for another example, see Rueda (1984). Teachers and students do not succeed separately from one another. When language minority students are achieving poorly, regular education teachers or bilingual special education teachers should not quickly attribute this performance to students' characteristics or to 
their behavior alone. The teachers must determine whether their instructional approaches are appropriate for those students, and then adjust accordingly.

\section{INSTRUCTION FOR DEVELOPING SOCIAL SKILLS}

\section{The Role of Stress}

The role of stress in precipitating social and emotional problems in children has been the subject of recent study. In determining the relationship between life events and their effects on children, three sources of stress-poverty, transition into the dominant American culture, and school failure-have particular importance for bilingual special education students.

\section{Poverty}

Although language minority students come from various socioeconomic backgrounds, a great majority live in urban settings and are subject to stress because of poverty. Canino, Early, and Rogler (1980) found that Hispanic children living in urban areas experience greater stress than Anglo children, which makes them more vulnerable to mental illness. Bryde (1971) reported that Native American adolescents in urban areas show a significantly higher incidence of feelings of alienation from both Indian and majority cultures. Similarly, Chinese American students in ghetto areas have been found to experience more stress and feelings of loneliness, anxiety, and isolation than their ethnic peers in suburban environments (Sue \& Frank, 1973).

\section{Transition}

Another source of stress has been found for children who have to make quick changes from one culture to another. For example, refugee children involved in war have experienced malnutrition, the dangers of death, and the severance of family ties and the loss of friends (Brower, 1980). The resulting instability may be the primary cause of the high rates of psychoses and character disorders that have been reported for Vietnamese and Cambodian children (Le, 1983).

A less extreme form of this type of stress is the conflict children experience when they try to rationalize their conformity to values accepted in the American cultures with those of their parents (Trankina, 1983). For example, Sue and Chin (1983) found that conflicts occurred when Chinese American adolescents had achieved different degrees of acculturation than their parents. In short, extreme changes in the ways in which children are accustomed to living can result in adjustment problems.

\section{School Failure}

In addition to difficulties at home are the problems children experience in school because they may lack role models to help them acquire behaviors that are acceptable in the new culture. The research literature concerning teacher referral to special education clearly shows that students are judged according to standards that teachers believe are important for classroom functioning. For example, Mercer (1973) found in referral documents that teachers more often mentioned problems such as not paying attention, poor work habits, and poor social relationships for students classified as mentally retarded as compared to those who were found ineligible. It is important to recognize the possibility that the standards teachers use to judge these behaviors are different from those accepted in a minority language student's community.

\section{Questions}

If one accepts the above proposition, several questions concerning children's misbehaviors in the school setting must be asked before referring students for special education and after placement in a successful mainstream experience. Guidance in developing these questions comes from theory and research in the area of social skills development.

For our discussion, social skills refer to “ . . . children's ability to organize cognitions and behaviors into an integrated course of action directed toward culturally acceptable social or interpersonal goals" (Ladd \& Mize, 1983, p. 127). In this definition, the term culturally acceptable poses a fundamental question: Who is to define what is culturally acceptable? It is clear, however, that students must meet expectations that may be foreign to them. Thus, Gresham and Elliot (1984) have posed another question in determining the causes of students' apparent inability to perform a behavior: Do students have the necessary skills to interact appropriately with peers or do they know the critical steps in the performance of the skill?

This question shifts the focus from students either being unwilling or incapable of behaving to one of teachers neces- 
sarily verifying whether students indeed have acquired the behavior and know under what conditions the behavior would be acceptable. Once the cause of the inappropriate behavior has been determined, teachers can begin developing and carrying out strategies to teach the behavior in a specific context, and eventually in generalized ones.

This approach is positive because students are assumed to be able to learn behaviors that will help them adapt to various social situations. Cartledge and Milburn (1983) have provided an extensive discussion of the validity of this assumption. Besides helping to remediate deficiencies, an approach like this can be preventive by instructing students in behaviors that may be expected of them in the future.

New York City school teachers, for example, often instruct language minority students, many of whom have experienced adjustment problems in the classroom. To what extent have any of these students been given the opportunity. to observe, question, and practice the behaviors acceptable in the classroom? Given the pressures of presenting an instructional program to 30 or more students, it probably is difficult to systematically teach social skills such as appropriately asking questions rather than calling out. But, by not doing so, teachers may be making an erroneous conclusion that the students have behavioral problems. Rather, the root of the problem can be traced to the student's never having had the chance to learn what is acceptable.

\section{Answers}

As teachers begin presenting new social behaviors to students, they may find that students are unable to learn them because they are anxious or easily distracted. As mentioned previously, some bilingual special educators have suggested that minority group students may have learning styles that do not fit in well with the way in which many teachers conduct instruction in the classroom (Almanza \& Mosley, 1980). For example, students in special classes probably have experienced considerable difficulty developing good peer relationships; teachers have mentioned these problems when referring students for special education (Mercer 1971, 1973). If the social skill being taught is how to play appropriately with peers, it may not be surprising that special education students show reluctance to learn those skills because they will have to perform them in an undesirable situation. Teachers will have to not only demonstrate and coach the students about the appropriate behavior but also reduce the students' anxieties by slowly introducing them to situations in which they will interact with their peers.
Sometimes teachers observe that students do not perform particular behaviors at desired levels. Because students have performed the behavior at least once, the problem is not one of a social skill deficit but, rather, a performance deficit (Gresham \& Elliot, 1984). The cause of this deficit has been attributed to two sources: (1) a lack of motivation, or (2) the absence of opportunity to perform the behavior.

In the former case, when students behave appropriately, teachers should praise them or use any of the other contingent reinforcement techniques that have been suggested in the special education literature (e.g., MacMillan, 1973), and specifically for instruction in social skills (e.g., Cartledge \& Milburn, 1983; Gresham, 1981; Ladd \& Mize, 1983; Rathjen, 1984). In creating opportunities for a behavior to occur, teachers could encourage classmates to work cooperatively with and play with these students (Strain, Shores, \& Timm, 1977).

We have presented only the basic principles for implementing a social skills program, assessing whether a student has acquired the skill, and teaching new skills to students. Teachers-especially bilingual special education teachersmust become familiar with these principles because, if our hypothesis is confirmed for only a small number of students, those students will be given the skills to succeed, rather than fail, in regular classrooms.

\section{CONCLUSION}

The field of bilingual special education is still in the process of establishing its identity. We have described the basis for its origin and its unique contribution in serving the special needs of students from linguistically and culturally different backgrounds. Given the continued over-representation of these students in special education classes, however, we also have suggested that the field move in the direction of a preventive service delivery model. The role of bilingual special education teachers and support personnel broadens from serving students once assigned to special education to greater involvement in consultation with regular classroom teachers.

We have identified promising lines of research and resulting teaching approaches. The most suitable approaches provide students with opportunities for greater verbal and social interaction with both teachers and peers, are experiential in nature, are culturally relevant and meaningful to students, and emphasize the acquisition of social skills. As these various approaches are more widely implemented, they can be empirically validated for different age groups, locales, 


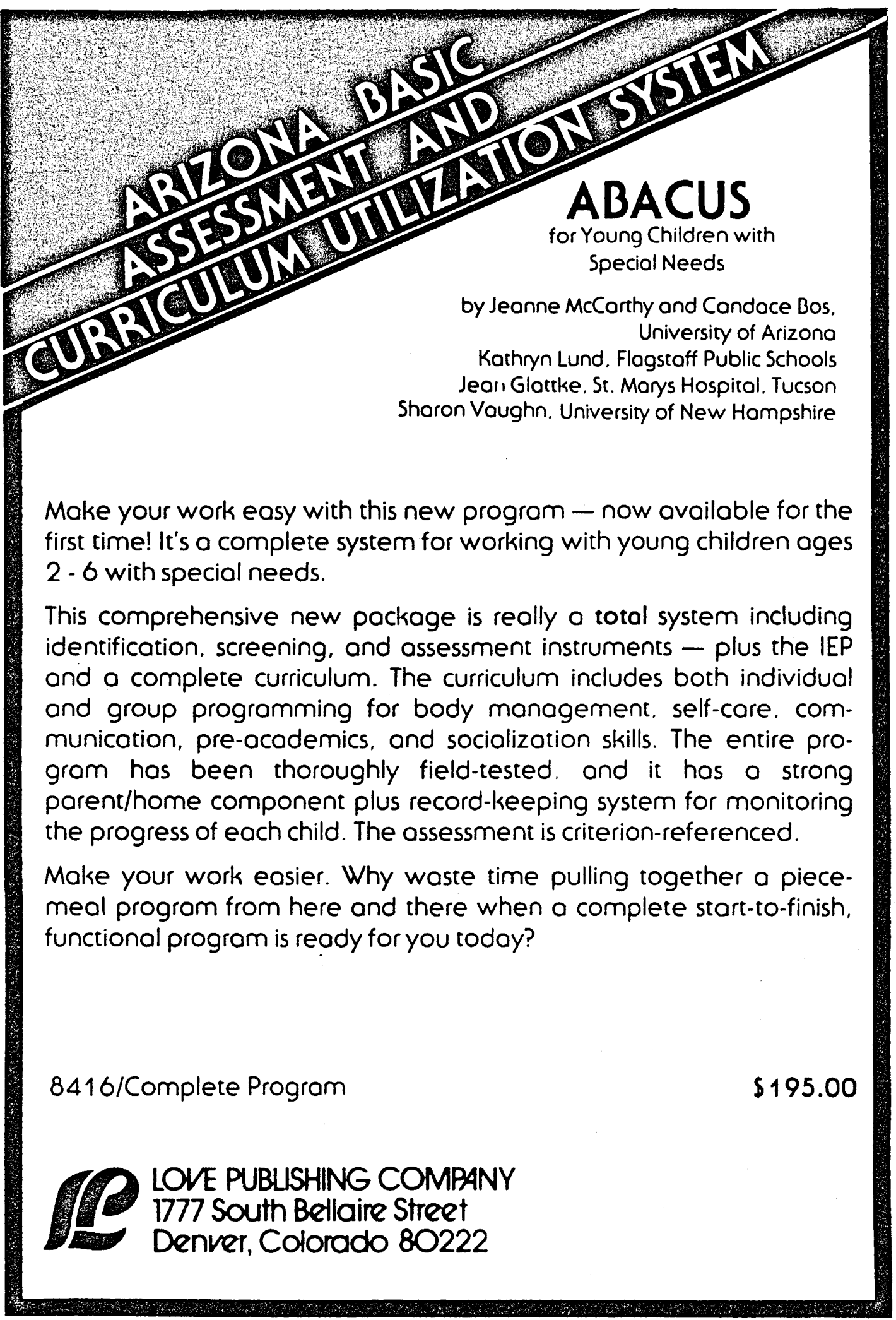


and ethnics groups. Progress in this direction will help schools achieve the difficult goal of appropriately educating all children, whether they are handicapped or not.

\section{REFERENCES}

Almanza, H. P., \& Mosley, W. J. (1980). Curriculum adaptations and modifications for culturally diverse handicapped children. Exceptional Children, 46, 608-614.

Ambert, A., \& Dew, N. (1982). Special education for exceptional bilingual students: A handbook for educators. Milwaukee: Midwest National Origin Desegregation Assistance Center.

Baca, L. M., \& Cervantes, H. T. (1984). The bilingual special education interface. St. Louis: Times Mirror/Mosley.

Brower, I. C. (1980). Counseling Vietnamese. Personnel \& Guidance Journal, 7, 646-652.

Bryde, J. (1971). Indian students and guidance. Boston: Houghton Mifflin.

Canino, I. A., Early, B. F., \& Rogler, L. H. (1980). The Puerto Rican child in New York City: Stress and mental health (Monograph No. 4). New York: Hispanic Research Center, Fordham University.

Cartledge, G., \& Milburn, J. F. (1983). Social skill assessment and teaching in the schools. In T. R. Krathochwill (Ed.), Advances in school psychology, Vol. III (pp.175-235). Hillsdale, NJ: Erlbaum.

Chin, J. L. (1981). Diagnostic considerations in working with Asian-Americans. American Journal of Orthopsychiatry, 53 (1), 100-109.

Cummins, J. (1980). Psychological assessment of immigrant children: Logic or intuition? Journal of Multilingual and Multicultural Development, 1, 97-111.

Cummins, J. (1984). Bilingualism and special education: Issues in assessment and pedagogy. Clevedon, Avon, England: Multilingual Matters.

Davis, W. E. (1978). A comparison of teacher referral and pupil self-referral measures relative to perceived school adjustment. Psychology in the Schools, 15, 22-26.

DeAvila, E., \& Duncan, S. E. (1981). Bilingualism and the metaset. In R. Duran (Ed.), Latino language and communicative behavior. Norwood, NJ: Ablex.

DeAvila, E., \& Duncan, S. E. (1982). Finding out/Descubrimiento. San Rafael, CA: Linguametrics Group.

Dunn, L. M. (1968). Special education for the mildly retarded-Is much of it justifiable? Exceptional Children, 35, 5-22.

Gallimore, R., Boggs, S., \& Jordan, C. (1974). Culture behavior and education: A study of Hawaiian Americans. Beverly Hills, CA: Sage.

Gallimore, R., \& Tharp, R. G. (1981). The interpretary of elicited imitation in a standardized context. Language Learning, 31, 369-392.

Gallimore, R., Tharp, R. G., Sloat, K. C. M., \& Klein, T. W. (1982). Analysis of reading achievement test results for the Kamehameha early education project: 1972-1979, KEEP Technical Reports \#95. Honolulu: Kamehameha Early Education Project.

Gregory, M. K. (1977). Sex bias in referrals. Journal of School Psychology, $15,5-8$.

Gresham, F. M. (1981). Social skills training with handicapped children: A review. Review of Educational Research, 51, 139-176.

Gresham, F. M., \& Elliot, S. N. (1984). Assessment and classification of children's social skills: A review of methods and issues. School Psychology Review, 13, 292-301.

Ladd, G. W., \& Mize, J. (1983). A cognitive-social learning model of social-skill training. Psychological Review, 90, 127-157.

Langdon, H. W. (1983). Assessment and intervention strategies for the bilingual language-disordered student. Exceptional Children, 50, 3746.
Le, D. D. (1983). Mental health in Vietnamese children. In G. F. Powell (Ed.), The psychosocial development of minority group children (pp. 373-384). New York: Brunner/Mazel.

MacMillan, D. L. (1971). Special education for the mildly retarded: Servant or savant. Focus on Exceptional Children, 2, 1-11.

MacMillan, D. L. (1973). Behavior modification in special education. New York: Macmillan.

MacMillan, D. L. (1982). Mental retardation in school and society (2nd ed.). Boston: Little, Brown.

Mercer, J. R. (1971). The meaning of mental retardation. In R. Koch \& J. C. Dobson (Eds.), The mentally retarded child and his family: A multidisciplinary handbook (pp. 23-46). New York: Brunner/Mazel.

Mercer, J. R. (1973). Labelling the mentally retarded. Berkeley, Los Angeles: University of California Press.

Meyers, C. E., MacMillan, D. L., \& Yoshida, R. K. (1978). Validity of psychologists' identification of EMR students in the perspective of the California decertification experience. Journal of School Psychology, 16, 237-244.

Omark, D. R., \& Erickson, J. G. (1983). The bilingual exceptional child. San Diego: College Hill Press.

Ortiz, A. (1984). Language and curriculum development for exceptional bilingual children. In P. C. Chinn (Ed.), Education of culturally and linguistically different exceptional children (pp. 77-100). Reston, VA: Council for Exceptional Children.

Ortiz, A., \& Yates, J. R. (1981). The incidence of exceptionality among Hispanics: Implications for manpower planning. Austin, TX: Texas Education Agency.

Perlman, R., Zabel, M. K., \& Zabel, R. (1982). Special education for exceptional bilingual students: $A$ handbook for educators. Dallas: Evaluation, Dissemination, and Assessment Center.

Rathjen, D. P. (1984). Social skills training for children: Innovations and consumer guidelines. School Psychology Review, 13, 302-310.

Rodriguez, R. (1982). Mainstreaming a multicultural concept into special education: Guidelines for teacher trainers. Exceptional Children, 49, 220-227.

Rueda, R. (1984). Cognitive development and learning in mildly handicapped bilingual children. In P. C. Chinn (Ed.), Education of culturally and linguistically different exceptional children (pp. 63-76). Reston, VA: Council for Exceptional Children.

Strain, P. S., Shores, R. E., \& Timm, M. A. (1977). Effects of peer social initiations on the behavior of withdrawn preschool children. Journal of Applied Behavior Analysis, 10, 289-298.

Sue, S., \& Chin, R. (1983). The mental health of Chinese American children: Stresses and resources. In G. F. Powell (Ed.), The psychosocial development of minority group children (pp. 385-397). New York: Brunner/Mazel.

Sue, D., \& Frank, A. (1973). A topological approach to the psychological study of Chinese and Japanese American college males. Journal of Social Issues, 29, 129-148.

Tharp, R. G. (1982). The effective instruction of comprehension: Results and description of the Kamehameha early education program. Reading Research Quarterly, 17, 503-527.

Tharp, R. G., \& Gallimore, R. (1976). The uses and limits of social reinforcement and industriousness for learning to read. ERIC Document ED 158-861.

Trankina, F. J. (1983). Clinical issues and techniques in working with Hispanic children and their families. In G. F. Powell (Ed.), The psychosocial development of minority group children (pp. 307-329). New York: Brunner/Mazel.

Tucker, J. (1980). Ethnic proportions in classes for the learning disabled: Issues in nondiscriminatory assessment. Journal of Special Education, 14, 93-105. 